\title{
A review on trade-off analysis of ecosystem services for sustainable land-use management
}

\author{
DENG Xiangzheng ${ }^{1,2}$, LI Zhihui $^{1,2,3}$, John GIBSON ${ }^{4}$ \\ 1. Institute of Geographic Sciences and Natural Resources Research, CAS, Beijing 100101, China; \\ 2. Center for Chinese Agricultural Policy, CAS, Beijing 100101, China; \\ 3. University of Chinese Academy of Sciences, Beijing 100049, China; \\ 4. Department of Economics, The University of Waikato, Hamilton, New Zealand
}

\begin{abstract}
Ecosystem services are substantial elements for human society. The central challenge to meet the human needs from ecosystems while sustain the Earth's life support systems makes it urgent to enhance efficient natural resource management for sustainable ecological and socioeconomic development. Trade-off analysis of ecosystem services can help to identify optimal decision points to balance the costs and benefits of the diverse human uses of ecosystems. In this sense, the aim of this paper is to provide key insights into ecosystem services trade-off analysis at different scales from a land use perspective, by comprehensively reviewing the trade-offs analysis tools and approaches that addressed in ecology, economics and other fields. The review will significantly contribute to future research on trade-off analysis to avoid inferior management options and offer a win-win solution based on comprehensive and efficient planning for interacting multiple ecosystem services.
\end{abstract}

Keywords: ecosystem services; trade-offs; land-use management; scale; integrated modeling; multi-criteria analysis; efficiency frontier

\section{Introduction}

Ecosystem services, which are broadly defined and extensively identified as the benefits obtained either directly or indirectly from ecosystems, are of great significance to human wellbeing. Ecosystem services flow into human society and provide fundamental life-support for human civilization. From clean water supply to erosion control, from food provision to climate regulation, from recreation to scenic beauty, all humans' life needed are provided by Earth's ecosystems (Daily et al., 1997). Since the concept of ecosystem being put forward by Tansley (1935), the study of ecological system has gradually become a scientific framework, and has been further strengthened since the end of the 20th century. With varying attentions and perspectives, from the biological basis to economic concerns, the

Received: 2016-02-02 Accepted: 2016-03-15

Foundation: China National Natural Science Funds for Distinguished Young Scholar, No.71225005; The Key Project in the National Science \& Technology Pillar Program of China, No.2013BACO3B00

Author: Deng Xiangzheng, PhD and Professor, land use change, global change and regional sustainable development. E-mail: dengxz.ccap@igsnrr.ac.cn 
concepts and evaluations of ecosystem services have been evolved through various research projects (Costanza et al., 1998; MEA, 2005; TEEB, 2010; De Groot et al., 2010b). Most of these research efforts were concentrated on the evaluation and mapping of the biophysical or economic values of ecosystem services at different scales, and the impact mechanisms of human activities and natural changes (Li et al., 2013; Deng et al., 2013), shedding lights on the identification of the benefits that human society receive from the nature and providing information for decision making. Clarifying the current situation of ecosystem services is a prerequisite for further analysis and solutions identification.

In real world contexts, as a kind of human civilization, the land-use management activities have profoundly altered the ecosystems. Currently, there is a trend that an ever-large amount of ecosystem goods and services have greatly benefited humans. However, the capacity of global ecosystems for sustainable development is simultaneously degrading, leading to unintentional consequences that will potentially jeopardize the future land-use options (World Bank, 2008). Confronting the global challenges that land use changes substantially affect and alter ecosystem services, trade-off analysis on ecosystem services associated with decisions between land use alternatives has become the focus of land-use management (Ryffel et al., 2014). In order to avoid unwanted and possibly irreversible effects of land-use change, sustainable land-use management should assess and manage inherent trade-offs between meeting the site-specific immediate human requirements and maintaining the long-term ecosystem services provisions. Trade-offs will arise if particular land-use management decisions are made, which will result in changes of the types, magnitudes and interactions of ecosystem services. In addition, since each ecosystem service is not independent, but instead exhibits complex interactions, which will further lead to different environmental or socioeconomic outcomes related to different individuals or groups (Rodríguez et $a l ., 2006)$. Over time, in spite of the great progress and success in the assessment of ecosystem services trade-offs, the practical application in land-use management decision is limited (Daily et al., 2009). The underlying reason is that most studies have been focused on one or a few services without considering the interdependence and highly non-linear relationships among the ecosystem services (Ring et al., 2010). Land-use management and decision makings with focus only on one type of ecosystem services without considering others will result in policy failure. In this sense, the understanding and knowledge about inter-linkages and potential trade-offs among different ecosystem services should be deepened and expanded to explore new insights in innovations related to institutions and governance (Elmqvist et al., 2013).

Although trade-offs analysis has become a hot topic in ecosystem services researches, few studies were conducted across disciplines. This study aims to explore the most frequent ecosystem services trade-offs associated with land-use practices and management, and compare techniques that measure trade-offs among ecosystem services across spatial and temporal scale based on comprehensive revisits to relevant researches. Firstly, we summarize the definitions and characteristics of ecosystem services trade-offs, then recognize trade-offs among ecosystem services at different scales. Subsequently, we elaborate the technics in different disciplines that are applied to investigate and measure the trade-offs for decision makings. Based on the review works, it will provide a comprehensive framework for future researches on ecosystem services trade-offs, which is critical to decision making 
for sustainable land-use management.

\section{Trade-offs of ecosystem services}

\subsection{Definitions of trade-offs}

Trade-off is a fundamental concept in economics, while being especially applied in an evolutionary context (Garland, 2014). In economic context, a trade-off is commonly expressed as the opportunity cost which is the preferred alternative when taking an economic decision, deriving from the idea that resources are scarce, which means to obtain more of one scarce resource, an individual or group collectively must give up some amount of another scarce good (De Groot et al., 2010a). In the ecosystem services context, the definition of trade-offs is mainly derived from the Millennium Ecosystem Assessment (MA), which is defined as management choices that intentionally change the services provided by ecosystems (MA, 2005a). In addition, The Economics of Ecosystems and Biodiversity (TEEB) described the trade-offs of ecosystem services as the way one ecosystem service responds to the changes in another service (TEEB, 2010). There are also some refined definitions of trade-offs, indicating the interactions among ecosystem services that result in the increasing provision of one ecosystem service at the cost of other services (Haase et al., 2012). Generally, trade-offs of ecosystem services occurs when human interventions enhance the output of an ecosystem service while negatively affect the provision of other services (De Groot et al., 2010a; Elmqvist et al., 2013).

\subsection{Recognitions of trade-offs}

Over time, socioeconomic development and human wellbeing are heavily relying on the provision of natural ecosystem services. On one hand, some of the ecosystem services functions are treated with priority and are intentionally modified due to their critical and important roles in the delivery of goods and services to support the human society, on the other hand, however, some of other services are ignored and damaged (Deng et al., 2011; Seppelt et al., 2013). Ecosystem is of extreme complexity and of great spatial and temporal variation in different ecological contexts. Identifying the specific trade-offs among different types of ecosystem services at different scales would help to convey information in a clear manner and provide decision-making framework about ecosystem services across geographic, ecological and socioeconomic dimensions (Ruhl et al., 2007; Tallis et al., 2008). In addition, it can also facilitate scientists and policy makers a better understanding of the potential consequences of unbalanced treatment of the ecosystem services in the process of land-use management (Haase et al., 2012).

\subsubsection{Trade-offs in ecosystems}

Considering the complexity and interactions of the ecosystems services for the human society, researches on the trade-off analysis between the provisioning and regulating services and investigations on the relationship of multiple ecosystem services and biodiversity are provoking. Agroecosystem is a good example in this case (Bennett and Balvanera, 2007; Nelson et al., 2008; Ring et al., 2010; TEEB, 2010; Elmqvist et al., 2013).

Agricultural land covers about 35\% of the Earth's terrestrial surface (MA, 2005c), pro- 
viding a series of provisioning (e.g., food, wood, and water), regulating (e.g., climate, carbon, and erosion), supporting (e.g., pollination, biodiversity/habitat), and cultural (e.g., recreation and education) services (Power, 2010). Over the past decades, humans changed the Earth's surface extensively for agriculture activities to meet the increasing demand for provisioning services, which severely affect the current and future generation of many regulating services and biodiversity (Bennett and Balvanera, 2007). For agroecosystem, the typical problem is that agricultural intensification and centralization related to the provisioning ecosystem services for higher macro-economic output usually reduce or damage other ecosystem services related to the ecosystem regulation and maintenance, as well as cultural services (Kirchner et al., 2015).

There are several studies explicitly analyzed the possible trade-offs among ecosystem services for agroecosystems. Specific trade-offs have been identified, such as the interactions between agricultural production and regulating services, e.g. sediment yield (Swallow et al., 2009) and carbon sequestration (Crossman et al., 2011). Biodiversity conservation is also commonly viewed as trade-off with agricultural production. Biodiversity is not equated to a specific ecosystem service or bundle. Most studies tried to investigate the trade-offs between biodiversity conservation and bundles of ecosystem services in agroecosystems. Barraguand et al. (2011) explicitly analyzed the trade-offs between valued agricultural production and biological conservation at the landscape scale. Mason et al. (2012) revealed that the investment directed into mitigating the impacts of agriculture on ecosystem services rather than biodiversity restoration would result in lower biodiversity. One research examined the potential trade-offs between agricultural production and biodiversity benefits, revealed that the benefit gained from an increase in biodiversity would outweigh the loss of returns from agricultural production (Dymond et al., 2012).

Little evidence and quantitative analysis on the interactions and linkages among ecosystem services bundles had been recognized as a major research gap regarding ecosystem services (Carpenter et al., 2009) and resulted in mixed conclusions (Bohensky et al., 2006). Recently, in order to provide implications for sustainable land-use management, researches on the types of interactions and the corresponding feedbacks among different ecosystem services are stimulated. For example, Brauman et al. (2007) revealed that water quality regulation services with other services, such as habit for biodiversity and climate regulation, can be co-delivered by vegetation, requiring the analysis of trade-offs among multiple services (Butler et al., 2013). It has been a major research priority to consider biodiversity conservation bundles and ecosystem services bundles during payment implementation (Wendland et al., 2010). In addition, some studies have revealed that when taking multiple services into consideration, the outcomes with maximized net gains of land-use management will be achieved more efficiently (Crossman and Bryan, 2009).

Intensive land-use change and management have been recognized as the major drivers that alter ecosystem services provision from agroecosystems (Sheng et al., 2011; Bryan, 2013). Wang et al. (2015) quantified the multiple ecosystem services in the Sanjiang Plain of China and concluded that the significant loss of ecosystem carbon stocks and natural habitats with grown food production was due to the extensive land conversion from natural wetlands to cultivated land. Similarly, Haines-Yong et al. (2012) confirmed a trade-off between the provisioning services ("crop-based production") and regulating services ("habitat diver- 
sity"). Also, during the process of ecological restoration, which converted the agricultural land back into natural ecosystems, trade-offs can be found among different ecosystem services, such as trade-off between biodiversity and salinity mitigation (Maron and Cockfield, 2008), between carbon sequestration and species conservation (Nelson et al., 2008), food production (Paterson and Bryan, 2012), and water supply (Chisholm, 2010). While, as humans play a critical role in managing the agroecosystem, political practices, socioeconomic incentives and technological progresses are likely to influence the quantity and quality of ecosystem services, which will further affect the direction of trade-offs (Nelson et al., 2009). Compared to the results of the research conducted by Wang et al. (2015), the study in the Loess Plateau of China by Lü et al. (2012) showed an opposite result, indicating synergy between food production and ecosystem carbon stocks with the conversions from farmland to woodland and grassland, which can be contributed to agricultural technological growth, improvement of agricultural management and production efficiency (Lü et al., 2012). Nelson et al. (2009) also identified that policy interventions could modify the negative trade-offs between commodity production and other ecosystem services and also biodiversity conversions. Maes et al. (2012) confirmed that there exist trade-offs among provisioning ecosystem services, regulation services and biodiversity conservation from agroecosystems, while he emphasized that trade-offs can be mitigated through specific management measures, such as increase cropping diversities and plant buffer strips. In this sense, trade-offs between agricultural production and other ecosystem services are not inevitable. Analysis on yields from agroecosystems indicated that with efforts on practice to conserve ecosystem services through measures, such as conservation tillage, crop diversification and biological control, ecosystem services trade-offs would be mitigated, with even improvements in yields (Badgley et al., 2007). These analyses suggest trade-off analysis should be incorporated into the land-use management decision making process, which can make a 'win-win' situation possible, where provisioning services are maintained and enhanced whilst other ecosystem services are supported.

\subsubsection{Trade-offs of ecosystem services at different scales}

The recognition of trade-offs should be conducted at different scales. It is commonly acknowledged that ecosystem services trade-offs occur at different spatial and temporal scale (Rodríguez et al., 2006; Power, 2010) and vary across both space and time (Holland et al., 2011), which increase more uncertainty to be managed. In addition, trade-off analysis from other perspectives are also proposed to be of great significance to land-use management and decision making, such as trade-offs among different stakeholders (Ring et al., 2010) and the reversibility of ecosystem services (Rodríguez et al., 2006).

(1) Trade-offs at time scale. Trade-offs at time scale arises when policy-makers make choices between current and future benefits. Identifying such trade-offs can help policy-makers understand that management decisions should consider the long-term effects of preferring the short-term provision of one ecosystem services at the expense of future use of this same service or other services (Rodríguez et al., 2006). Rodríguez et al. (2005) elaborated a broad topic about the temporal trade-offs during decision makings, which revealed that there would be many important trade-offs between current use of nonrenewable resources and their future use. It was pointed out that slowly natural processes, such as soil formation, groundwater supply and genetic diversity generation that underlay supporting 
services, were always being ignored since that they were difficult to be detected and quantified, which would seriously damage the long-run sustainable provision of ecosystem services (Rodríguez et al., 2005). For example, the collective activities of farmers to replace the original woody vegetation with pasture and corps for the short-term increase in agricultural production led to the water table being moved toward the surface, bringing salt upward through the soil, which finally resulted in land salinization in the long-term future (Greiner and Cacho, 2001; Briggs and Taws, 2003). Regarding the natural processes, there exist a great deal of uncertainties associated with large time lags in the feedback between changes in ecosystem process and other factors, posing much more difficulties in forecasting eventual outcomes and identifying the critical thresholds of ecosystem services (Holling, 1973; Rockström et al., 2009). For a balanced feedback loop during the resources management, the ability to recognize the trade-offs between current and future desirable states and 'time preferences' for ecosystem services becomes important and critical to make better decisions on land-use management (van den Belt et al., 2013).

(2) Trade-offs at spatial scale. Spatial trade-offs could be simply recognized as benefits here while cost there (Ring et al., 2010), it occurs spatially between different landscapes, ecosystems, communities and even countries. For example, the improvement in water productivity with more agricultural inputs in the upstream will consequentially impact the water quality regulation services and incur costs in the downstream (Pattanayak, 2004). Such trade-offs have been illustrated specifically in the agricultural production in the USA, where the highly intensive agriculture relied greatly on artificial fertilization and finally led to massive negative impacts on the fisheries in the Gulf of Mexico (Tilman et al., 2002; Cumming, 2005). Spatial trade-offs are also well-known in economics, the environmental economists use spatial externality to indicate the positive or negative effects of land-use management decisions on ecosystem services in extended areas than those ecosystem services of where the decisions incurred that cost or benefit (Tietenberg, 1988). For example, the extensive division of water from rivers for drinking or agriculture irrigation in the upper regions will trigger water scarcity in the regions lower down the watershed (Falkenmark, 2003), while the local cost to conserve the biodiversity will benefit the global (Ring, 2008). The need to account for the spatial effects outside traditional geopolitical boundaries when facing ecosystem services decisions has been recognized by many managers, while practically it was rare that managers would give consideration to large-scale benefit at the cost of local wellbeing. It implies that incentives are needed to encourage managers think broadly to integrate experiences of small-scale "win-win" solutions to solve large-scale and macro problems (Rodríguez et al., 2005).

(3) Trade-offs among stakeholders. Ecosystem services trade-offs among stakeholders mean that some stakeholders win while others lose, that is, one benefits from a particular ecosystem service at the cost of other individuals (Rodríguez et al., 2006). The UK National Ecosystem Assessment (UKNEA) defined such trade-offs as two outcomes: one is that the quality or quantity of an ecosystem service being utilized by one stakeholder was reduced or deteriorated due to others' utilization of that or other ecosystem services; the other one is that the utilization of ecosystem services by one stakeholder would lead to the decline of others' wellbeing (UKNEA, 2011). Different stakeholders derive wellbeing from a variety of ecosystem services based on their choices of development and management of particular 
services, which are strongly influenced by lots of factors, such as their beliefs, preferences and experiences over time (McShane et al., 2011). Trade-offs occur among different ecosystem services due to inherent biophysical constraints in time and over space, then the divergent preferences on ecosystem services of different stakeholders will trigger conflicts (Martín-López et al., 2012). For instance, land use activities in terrestrial ecosystems impact the water regulation services through hydrological processes, then it will arise the conflicts among a range of associated stakeholders that depend on terrestrial ecosystems and aquatic ecosystems (Silvestri and Kershaw, 2010). In this case, reconciling stakeholders' divergent preferences over ecosystem services with explicit recognition of the nature of biophysically based trade-offs is crucial to identify sustainable solutions (King et al., 2015). With stakeholders' preferences being valued and added into the trade-off analysis, it makes the values intrinsic to ecosystem services (Brauman et al., 2007), and most researchers recently thought that the values as sources of conflicts that should be separated with biophysical constraints (Mouchet et al., 2014; Yahdjian et al., 2015). Especially, Cavender-Bares et al. (2015) presented a sustainability framework that characterizes ecosystem services trade-offs in terms of two dimensions of ecosystem service conflicts: biophysical constraints, and divergent preferences and values of stakeholders. The framework enables the identification of driving factors of and direct visualization of trade-offs due to stakeholders' preferences at spatial or temporal scale (Cavender-Bares et al., 2015). King et al. (2015) further evaluated the utility of the framework for ecosystem services trade-off analysis with critical insights to clarify conflicts among stakeholders under different scenarios.

(4) Trade-offs in terms of reversibility. Reversibility of ecosystem services means the possibility of disturbed ecosystem service being reversed back to its original state once the perturbation ceased (Rodríguez et al., 2005). In addition that trade-offs effects can be felt over time and spatial scale, indeed, some trade-offs may be irreversible. Regarding that the ecosystem services may be changed irreversibly, the importance of thresholds has been highlighted in the Millennium Ecosystem Assessment (MA, 2005b). When a system crosses a threshold due to persistent or strong environmental or socioeconomic drivers, it will trigger great costs to society due to the irreversible loss in critical natural capital (Farley, 2012). Ring et al. (2010) interpreted the thresholds as resilience, which stands for a system's ability to adapt to the perturbations and stay persistent without changes. Further, considering the thresholds, they put forward four types of non-linear dynamics in ecosystems. It includes: a system with 'no-threshold effect', where it is revisable no matter how the changes in the controlling variables; a system with 'threshold, no alternate attractors', where slight changes in controlling variables will significantly alter the system while it is still revisable if changes pass the threshold; a system with 'threshold, alternate stable state', where it may be irreversible with large changes in the controlling variables that pass the thresholds; and a system with 'irreversible threshold change', where the changes shall not exceed thresholds to avoid irreversible situations (Ring et al., 2010). The existing of thresholds and relevant irreversible dynamic changes may curse various problems for sustainable development of socioecological systems, e.g. application of fertilizer in agricultural production that exceeds the thresholds will pose negative impacts on water quality. While with recognition of the thresholds, better management measures can be taken to shift the trade-off thresholds, such as that precise agriculture will achieve greater crop yield with same inputs, while with less damages to 
ecosystems (Cavender-Bares et al., 2015). Thus, being aware of how far-reaching the effect, whether the effect is reversible, and how quickly can it be reversed, managers can make decisions appropriately to mitigate negative effects and even achieve "win-win" situations (Rodríguez et al., 2005).

In dealing with the trade-offs in the context of ecosystem services, there exist multiple interactions and linkages among services at different scales that should be taken into consideration at first place, such as processes and management interventions of different stakeholders across various spatial and temporal scale. In addition, variations in the thresholds of ecosystems are closely related with the reversibility, making it difficult to estimate the ecological status. Facing the above issues, managers should complement their decisions with trade-offs at multiple spatial, temporal and stakeholder scales into consideration, with recognition of the threshold to minimize the negative effects of trade-offs.

\section{Quantification analysis of trade-offs}

Management of the complex socio-ecological system requires tools to depict trade-offs among ecosystem services. As reviewed above, the major barriers to effective management contribute to that services trade-offs differ across time and space, and that different groups of stakeholders possess different preferences for services. To deal with the barriers, researches in different disciplines have applied a variety of tools and approaches to quantitatively analyze these ecosystem service trade-offs. For a comprehensive knowledge of tools and approaches, we conduct a review of how ecosystem services trade-offs being analyzed at different scales from various perspectives.

\subsection{Mapping trade-offs via correlation analysis and cluster analysis}

GIS-based spatial mapping analyses are frequently applied to provide detailed information on ecosystem services indicators and further assist to understand and visualize potential trade-offs (Kirchner et al., 2015). For example, Maes et al. (2012) confirmed trade-offs between multiple ecosystem services and biodiversity with GIS-based spatial mapping and correlation analysis in Europe. Similarly, Maskell et al. (2013) identified intensive trade-offs between soil carbon storage and above-ground net primary production based on maps and pairwise correlations. The two examples above just investigated the trade-offs among multiple ecosystem services across space with no changes at time scale. While in practical terms, trade-offs are usually identified in response to land-use changes under particular management actions and measures or designed scenarios over time. Jiang et al. (2013) mapped changes in agricultural production, carbon storage and biodiversity, and further conducted spatial statistic analysis on the trade-offs at landscape scale in the UK during 1930-2000. In addition, trade-off analysis is mostly conducted from the perspective of biophysical supply side, while studies are scarcely conducted to assess and map ecosystem services trade-offs from the aspect of social demand side. To address both biophysical supply and social demand sides, Castro et al. (2014) identified ecosystem services trade-offs based on correlation analysis, both on the supply and the social demand sides, and analyzed spatial mismatches among the ecosystem services on biophysical, socio-cultural and economic dimensions within a spatial unit (Castro et al., 2014). 
Correlation analysis of the trade-offs based on mapping simply identifies the interactions between pairs of ecosystem services, while trade-offs and synergies are more generally found within the bundles of services, indicating that a more integrated perspective on bundles of services is required for trade-off analysis among ecosystem services (Haines-Young et al., 2012). Regarding the interactions among ecosystem services bundles, cluster analysis was mostly applied. Cluster analysis based on mapping is a powerful tool to identify ecosystem service bundle types and analyze ecosystem services trade-offs and synergies (Raudsepp-Hearne et al., 2010). Especially, it is a more appropriate way when prior knowledge about what the trade-offs involve is not available (Medcalf et al., 2014). Raudsepp-Hearne et al. (2010) applied the concept of ecosystem service bundles to analyze interactions among ecosystem services, in which cluster analysis determined the provision of all 12 ecosystem services and grouped the 137 municipalities into six data clusters. Also, Haines-Young et al. (2012) explored the trade-offs between the selected services with cluster analysis, in which seven spatially explicit clusters were distinguished with distinct evolutionary trajectories of ecosystem services.

GIS-based spatial mapping with accompanied correlation or cluster analysis on the interactions among ecosystem services is a useful tool to provide specific information for trade-off analysis. Nonetheless, it is criticized that there are some shortcomings, such as less focused on biodiversity, mostly dominated at regional scale, and rarely considered detailed bottom-up economic modeling of land-use management (Kirchner et al., 2015).

\subsection{Integrated modeling for trade-off analysis}

In comparison with the widely applied GIS-based tool for spatial ecosystem services trade-off mapping analysis, integrated modeling approach can deal with some shortcomings raised above, which not only allows for a spatially explicit quantification of the ecosystem services changes over time and space (Huber et al., 2013), but also can link disciplinary data and models to clarify complex interactions between the human society and the ecosystems (Falloon and Betts, 2010; Laniak et al., 2013). Recently, the integrated modeling approach has been widely applied in the assessment of trade-offs in ecosystem services (Nelson et al., 2009; Polasky et al., 2011; Willemen et al., 2012). For example, Briner et al. (2012) designed an integrative modeling framework-Alpine Land Use Allocation Model (ALUAM), which not only specifically considers the spatial scale at which decisions are made, but also the economic interdependencies among ecosystem services. Further, they applied the ALUAM to evaluate spatially explicit trade-offs among food provision, protection against natural hazards, carbon sequestration, and biodiversity in a mountain region in the Swiss Alps within designed scenarios (Briner et al., 2013).

Among the integrated modeling tools, the most currently available and applied tool is the Integrated Valuation of Ecosystem Services and Trade-offs (InVEST) (Nelson et al., 2009; Tallis et al., 2011), which was designed to inform decisions about resources management and planning. Nelson et al. (2009) applied InVEST to investigate the trade-offs between biodiversity conservation and ecosystem services under stakeholder-defined scenarios of land-use/land-cover change in the Willamette Basin. It showed that such trade-offs varied in different scenarios, suggesting that analyzing trade-offs between ecosystem services did great favor in more effective, efficient, and defensible decision makings (Nelson et al., 
2009). Goldstein et al. (2012) revealed the trade-offs between carbon storage and water quality and also between environmental improvement and financial returns under seven land-use planning scenarios based on InVEST, which support the implement of the plan for diversified agriculture and forestry management. However, Jackson et al. (2013) pointed out that InVEST was widely applied at large scale and with coarse resolution, in comparison, they designed the Polyscape tool, which can be used to disentangle spatially explicit ecosystem services trade-offs to support landscape management, from individual field scale through to catchments scale. Further, they compared the similarities and dissimilarities among different tools, such as Artificial Intelligence for Ecosystem Services (ARIES) tool, Envision tool, and the framework and models developed within Multiscale Integrated Earth Systems project (MIMES) (Jackson et al., 2013).

There has been great advances in the development and application of integrated modeling approach for ecosystem services and trade-off analysis, while comparing the dissimilarities among the integrated modeling tools, it can be noted that, considering the spatial differences and regional heterogeneities, there still exist space and opportunities for innovations on multi-scale and multi-regional integrated modeling frameworks for ecosystem services trade-off analysis at a higher spatial resolution (Crossman et al., 2013).

\subsection{Multi-criteria analysis of trade-offs}

Ecosystem management will inevitably involve conflicting objectives, trade-offs, uncertainties and conflicting value judgments (Sanon et al., 2012), making it a complex process for policy design for ecosystem management. To address above interdisciplinary and complex problems, multi-criteria analysis, as a tool that can take both ecological and socioeconomic criteria into consideration, is mostly applied to conduct ecological economic analysis (Huang et al., 2011; Fontana et al., 2013). Multi-criteria analysis had been applied in various disciplinary researches and recently been broadly introduced and utilized to solve the problems in ecosystem services management (Daily et al., 2009; Nelson et al., 2009). For example, Cheung and Sumaila (2008) applied the multi-criteria analysis to explore the trade-offs between conflicting conservation and socioeconomic objectives for tropical marine ecosystems management.

Traditional multi-criteria analysis deals with only the implicit trade-offs through introducing the weights expressed by the stakeholders (Van Huylenbroeck, 1997), to enhance the transparency, Sanon et al. (2012) assigned numerical values for ecosystem services to elaborate and quantify the trade-offs between the stakeholder's objectives based on a participatory approach (Sanon et al., 2012). In addition, combining the Geographical Information System (GIS) with multi-criteria analysis, Nguyen et al. (2015) proposed a spatial multi-criteria analysis, which integrates ecological aptitude, environmental impact and socio-economic feasibility criteria in a step-wise procedure to analyze objectives that affected by spatially-distributed diagnostic factors. Further, Vollmer et al. (2015) demonstrated an application of a four-step spatial multi-criteria analytical approach that involves scenario development, ecosystem service quantification and mapping, preference weighting, and optimization to maximize preferred ecosystem services while minimizing cost, which can support decision making for efficient polices to manage ecosystem services. 


\subsection{Trade-off analysis based on production theory}

Multi-criteria analysis has a long history of being applied to analyze the trade-offs in ecosystem services, in parallel, the production theory developed by the economics discipline has also been applied to production of ecosystem services (Barbier, 2007) and to examine services trade-offs (Naidoo and Ricketts, 2006). Production theory is a subfield of microeconomics that concerns trade-offs between different inputs for production, i.e. considering the process of different inputs being converted into different outputs (Varian and Repcheck, 2010). A production theory analysis can be linked not only to the ecosystem services with market value as inputs in the production function, but also to the others not connected to market output (Chee, 2004; Barbier, 2007). As that not all services can be simultaneously maximally delivered to humans, thus stakeholders must make decisions according to their preferences, then when applying production theory to ecosystem services trade-off analysis for decision making, the key principle is to achieve the sustainable and efficient delivery of multiple interacting services to human society (Tallis et al., 2008).

The Cobb-Douglas Production functions are the most widely used types to depicts the production theory (Chisasa and Makina, 2013), while it cannot cope with the complex systems that with multiple inputs/multiple outputs production systems that influenced by natural resources, external environmental attributes, and the preferences of land managers. To address the multiple-inputs/multiple outputs production functions, the efficiency frontier method has become popular (Grosskopf et al., 1992), which can be traced back to the ideas put forward by Farrell (Farrell, 1957). Specifically, the productive efficiency is treated as a relative concept, which can be illustrated as Pareto-efficient options for optimal utilization of two or more services, where the system cannot increase one service without sacrificing other services (Nelson et al., 2008; Polasky et al., 2008).

In recent years, the efficiency frontier analysis has been utilized in a variety of researches to examine trade-offs between different ecosystem services, especially in agro-ecosystems (Bekele et al., 2013; Balbi et al., 2015; Mastrangelo and Laterra, 2015). Lester et al. (2013) conducted a review on the ecosystem services trade-off analysis framework that based on economic theory, and summarized six common types of ecosystem service interactions based on the insights gained from frontier shapes, including non-interacting services, direct trade-off, convex trade-off, concave trade-off, non-monotonic concave trade-off, and backward S trade-off. All the frontier shapes focus on two dimensions, which are the easiest ways to visualize, while the concept and logit can be applied to trade-offs in multiple dimensions as well (Cavender-Bares et al., 2015). For example, to deal with the conflicts between the production of marketable ecosystem goods and the provision of non-marketed ecosystem services in agro-ecosystems, Bekele et al. (2013) combined the Soil and Water Assessment Tool (SWAT) model and the productive frontier analysis to analyze a 6-dimensional trade-offs between three provisioning services and three regulating services, which confirmed that provisioning and regulatory services aggregately formed a linear to convex ecological-economic production possibilities frontiers. The efficiency frontier is an effective method to judge the biophysical constraints of the ecosystem services production system, which combines with the information about value of services from stakeholders' perspective, and further identifies optimal management approaches that yield the greatest net 
benefits, while the problem that there may exist uncertainty about the production frontier and values still remains to be dealt with (Cavender-Bares et al., 2015)

\section{Conclusions}

For ensuring sustainable land-use management, it is critical to conduct trade-off analysis of ecosystem services closely associated with land-uses, which allows the decision-makers to better understand the corresponding consequences of different choices and achieve a solution to long-run sustainable development of socio-ecological systems.

Trade-offs arise when biophysical constrains change or humans make management interventions, which will change the types, magnitudes and interactions among services provided by ecosystems. Investigations on the trade-offs among individual ecosystem services and biodiversity are mostly provoked, further analysis on the interactions among ecosystem services bundles has also gained great achievements. On one hand, intensive land-use change and management are recognized as the major factors affecting ecosystem services provisions and incurring trade-offs, on the other hand, the major barriers that inhabit the sustainable resource planning and management contribute to ecosystem services trade-offs at different scales, which can be classified in terms of temporal and spatial scale, stakeholders' preference, and the degree of irreversibility. Thus, taking the ecosystem services trade-offs at different scales into consideration during decision-making is important for sustainable land use management to avoid negative effects and achieve synergetic outcomes.

In dealing with the problem of ecosystem services trade-offs, a wide variety of analytical tools and approaches have been developed and applied for management decisions, including the assessments that explicitly linked spatial information on service supply to conduct correlation or cluster analysis, the integrated modeling framework for the systemic assessment, and also approaches based on the multi-criteria decision theory and economic production theory. While, evaluation of trade-offs is complex due to the multiple dimensions, interactions, variations and uncertainties with different physical units across time and space, thus quantifying the non-linear dynamics of trade-offs between ecosystem services in the social-ecological systems driven by both biophysical drivers and management decisions still remains a big challenge for sustainable land-use management.

\section{Conflict of Interests}

The authors declare that there is no conflict of interests regarding the publication of this paper.

\section{References}

Badgley C, Moghtader J, Quintero E et al., 2007. Organic agriculture and the global food supply. Renewable Agriculture and Food Systems, 22(2): 86-108.

Balbi S, del Prado A, Gallejones P et al., 2015. Modeling trade-offs among ecosystem services in agricultural production systems. Environmental Modelling \& Software, 72: 314-326.

Bank W, 2008. Sustainable Land Management Sourcebook. Washington, DC: World Bank.

Barbier E B, 2007. Valuing ecosystem services as productive inputs. Economic Policy, 22(49): 178-229. 
Barraquand F, Martinet V, 2011. Biological conservation in dynamic agricultural landscapes: Effectiveness of public policies and trade-offs with agricultural production. Ecological Economics, 70(5): 910-920.

Bekele E G, Lant C L, Soman S et al., 2013. The evolution and empirical estimation of ecological-economic production possibilities frontiers. Ecological Economics, 90: 1-9.

Bennett E M, Balvanera P, 2007. The future of production systems in a globalized world. Frontiers in Ecology and the Environment, 5(4): 191-198.

Bohensky E L, Reyers B, Van Jaarsveld A S, 2006. Future ecosystem services in a Southern African river basin: A scenario planning approach to uncertainty. Conservation Biology, 20(4): 1051-1061.

Brauman K A, Daily G C, Duarte T K et al., 2007. The nature and value of ecosystem services: An overview highlighting hydrologic services. Annual Review of Environment and Resources, 32: 67-98.

Briggs S V, Taws N, 2003. Impacts of salinity on biodiversity: Clear understanding or muddy confusion? Australian Journal of Botany, 51(6): 609-617.

Briner S, Elkin C, Huber R et al., 2012. Assessing the impacts of economic and climate changes on land-use in mountain regions: A spatial dynamic modeling approach. Agriculture, Ecosystems \& Environment, 149: 50-63.

Briner S, Huber R, Bebi P et al., 2013. Trade-offs between ecosystem services in a mountain region. Ecology and Society, 18(3): 35 .

Bryan B A, 2013. Incentives, land use, and ecosystem services: Synthesizing complex linkages. Environmental Science \& Policy, 27: 124-134.

Butler J R, Wong G Y, Metcalfe D J et al., 2013. An analysis of trade-offs between multiple ecosystem services and stakeholders linked to land use and water quality management in the Great Barrier Reef, Australia. Agriculture, Ecosystems \& Environment, 180: 176-191.

Carpenter S R, Mooney H A, Agard J et al., 2009. Science for managing ecosystem services: Beyond the Millennium Ecosystem Assessment. Proceedings of the National Academy of Sciences, 106(5): 1305-1312.

Castro A J, Verburg P H, Martín-López B et al., 2014. Ecosystem service trade-offs from supply to social demand: A landscape-scale spatial analysis. Landscape and Urban Planning, 132: 102-110.

Cavender-Bares J, Polasky S, King E et al., 2015. A sustainability framework for assessing trade-offs in ecosystem services. Ecology and Society, 20(1): 17.

Chee Y E, 2004. An ecological perspective on the valuation of ecosystem services. Biological Conservation, 120(4): 549-565.

Cheung W W, Sumaila U R, 2008. Trade-offs between conservation and socio-economic objectives in managing a tropical marine ecosystem. Ecological Economics, 66(1): 193-210.

Chisasa J, Makina D, 2013. Bank credit and agricultural output in South Africa: A Cobb-Douglas empirical analysis. International Business \& Economics Research Journal (IBER), 12(4): 387-398.

Chisholm R A, 2010. Trade-offs between ecosystem services: Water and carbon in a biodiversity hotspot. Ecological Economics, 69(10): 1973-1987.

Costanza R, d'Arge R, De Groot R et al., 1998. The value of the world's ecosystem services and natural capital. Ecological Economics, 1(25): 3-15.

Crossman N D, Bryan B A, 2009. Identifying cost-effective hotspots for restoring natural capital and enhancing landscape multifunctionality. Ecological Economics, 68(3): 654-668.

Crossman N D, Bryan B A, de Groot R S et al., 2013. Land science contributions to ecosystem services. Current Opinion in Environmental Sustainability, 5(5): 509-514.

Crossman N D, Bryan B A, Summers D M, 2011. Carbon payments and low-cost conservation. Conservation Biology, 25(4): 835-845.

Cumming G, 2005. Ecology in global scenarios. Ecosystems and Human Well-being: 45.

Daily G C, Alexander S, Ehrlich P R et al., 1997. Ecosystem Services: Benefits Supplied to Human Societies by Natural Ecosystems. Ecological Society of America Washington (DC).

Daily G C, Polasky S, Goldstein J et al., 2009. Ecosystem services in decision making: Time to deliver. Frontiers in Ecology and the Environment, 7(1): 21-28.

De Groot R, Fisher B, Christie M et al., 2010a. Integrating the ecological and economic dimensions in biodiversity and ecosystem service valuation. In: The Economics of Ecosystems and Biodiversity (TEEB): Ecological and Economic Foundations. Earthscan.

De Groot R S, Alkemade R, Braat L et al., 2010b. Challenges in integrating the concept of ecosystem services and 
values in landscape planning, management and decision making. Ecological Complexity, 7(3): $260-272$.

Deng X Z, Li Z H, Huang J K et al., 2013. A revisit to the impacts of land use changes on the human wellbeing via altering the ecosystem provisioning services. Advances in Meteorology, 2013.

Deng X Z, Zhao Y H, Wu F et al., 2011. Analysis of the trade-off between economic growth and the reduction of nitrogen and phosphorus emissions in the Poyang Lake Watershed, China. Ecological Modelling, 222(2): 330-336.

Dymond J R, Ausseil A-G E, Ekanayake J C et al., 2012. Tradeoffs between soil, water, and carbon: A national scale analysis from New Zealand. Journal of Environmental Management, 95(1): 124-131.

Elmqvist T, Tuvendal M, Krishnaswamy J et al., 2013. Managing trade-offs in ecosystem services. In: Kumar P, Thiaw I (eds.). Values, Payments and Institutions for Ecosystem Management. Cheltenham: Edward Elgar Publishing, 70-89.

Falkenmark M, 2003. Freshwater as shared between society and ecosystems: From divided approaches to integrated challenges. Philosophical transactions of the Royal Society B: Biological Sciences, 358(1440): 2037-2049.

Falloon P, Betts R, 2010. Climate impacts on European agriculture and water management in the context of adaptation and mitigation: The importance of an integrated approach. Science of the Total Environment, 408(23): $5667-5687$.

Farley J, 2012. Ecosystem services: The economics debate. Ecosystem Services, 1(1): 40-49.

Farrell M J, 1957. The measurement of productive efficiency. Journal of the Royal Statistical Society. Series A (General): 253-290.

Fontana V, Radtke A, Fedrigotti V B et al., 2013. Comparing land-use alternatives: Using the ecosystem services concept to define a multi-criteria decision analysis. Ecological Economics, 93: 128-136.

Garland T, 2014. Quick guide: Trade-offs. Current Biology, 24(2): R60-R61.

Goldstein J H, Caldarone G, Duarte T K et al., 2012. Integrating ecosystem-service tradeoffs into land-use decisions. Proceedings of the National Academy of Sciences, 109(19): 7565-7570.

Greiner R, Cacho O, 2001. On the efficient use of a catchment's land and water resources: Dryland salinization in Australia. Ecological Economics, 38(3): 441-458.

Grosskopf S, Hayes KandYaisawarng S, 1992. Measuring economies of diversification: A frontier approach. Journal of Business \& Economic Statistics, 10(4): 453-459.

Haase D, Schwarz N, Strohbach M et al., 2012. Synergies, trade-offs, and losses of ecosystem services in urban regions: An integrated multiscale framework applied to the Leipzig-Halle Region, Germany. Ecology and Society, 17(3): 22.

Haines-Young R, Potschin M, Kienast F, 2012. Indicators of ecosystem service potential at European scales: Mapping marginal changes and trade-offs. Ecological Indicators, 21: 39-53.

Holland R A, Eigenbrod F, Armsworth P R et al., 2011. The influence of temporal variation on relationships between ecosystem services. Biodiversity and Conservation, 20(14): 3285-3294.

Holling C S, 1973. Resilience and stability of ecological systems. Annual Review of Ecology and Systematics, $1-23$.

Huang I B, Keisler J, Linkov I, 2011. Multi-criteria decision analysis in environmental sciences: Ten years of applications and trends. Science of the Total Environment, 409(19): 3578-3594.

Huber R, Bugmann H, Buttler A et al., 2013. Sustainable land-use practices in European mountain regions under global change: An integrated research approach. Ecology and Society, 18(3): 37.

Jackson B, Pagella T, Sinclair F et al., 2013. Polyscape: A GIS mapping framework providing efficient and spatially explicit landscape-scale valuation of multiple ecosystem services. Landscape and Urban Planning, 112: 74-88.

Jiang M K, Bullock J MandHooftman D A, 2013. Mapping ecosystem service and biodiversity changes over 70 years in a rural English county. Journal of Applied Ecology, 50(4): 841-850.

King E, Cavender-Bares J, Balvanera P et al., 2015. Trade-offs in ecosystem services and varying stakeholder preferences: evaluating conflicts, obstacles, and opportunities. Ecology and Society, 20(3): 25.

Kirchner M, Schmidt J, Kindermann G et al., 2015. Ecosystem services and economic development in Austrian agricultural landscapes: The impact of policy and climate change scenarios on trade-offs and synergies. Ecological Economics, 109: 161-174. 
Laniak G F, Olchin G, Goodall J et al., 2013. Integrated environmental modeling: A vision and roadmap for the future. Environmental Modelling \& Software, 39: 3-23.

Lester S E, Costello C, Halpern B S et al., 2013. Evaluating tradeoffs among ecosystem services to inform marine spatial planning. Marine Policy, 38: 80-89.

Li Z H, Deng X Z, Huang J K et al., 2013. Critical studies on integrating land-use induced effects on climate regulation services into impact assessment for human well-being. Advances in Meteorology, 1-14. doi: $10.1155 / 2013 / 831250$.

Lü Y, Fu B, Feng X et al., 2012. A policy-driven large scale ecological restoration: Quantifying ecosystem services changes in the Loess Plateau of China. PloS One, 7(2): e31782.

MA, 2005a. Ecosystems and Human Well-being. Washington, DC: Island Press.

MA, 2005b. Ecosystems and Human Well-being: Current State and Trends. Washington, DC: Island Press.

MA, 2005c. Our Human Planet: Summary for Decision-makers. Island Press.

Maes J, Paracchini M, Zulian G et al., 2012. Synergies and trade-offs between ecosystem service supply, biodiversity, and habitat conservation status in Europe. Biological Conservation, 155: 1-12.

Maron M, Cockfield G, 2008. Managing trade-offs in landscape restoration and revegetation projects. Ecological Applications, 18(8): 2041-2049.

Martín-López B, Iniesta-Arandia I, García-Llorente M et al., 2012. Uncovering ecosystem service bundles through social preferences. PloS One, 7(6): e38970.

Maskell L C, Crowe A, Dunbar M J et al., 2013. Exploring the ecological constraints to multiple ecosystem service delivery and biodiversity. Journal of Applied Ecology, 50(3): 561-571.

Mason N W, Ausseil A-G E, Dymond J R et al., 2012. Will use of non-biodiversity objectives to select areas for ecological restoration always compromise biodiversity gains? Biological Conservation, 155: 157-168.

Mastrangelo M E, Laterra P, 2015. From biophysical to social-ecological trade-offs: Integrating biodiversity conservation and agricultural production in the Argentine Dry Chaco. Ecology and Society, 20(1): 20.

McShane T O, Hirsch P D, Trung T C et al., 2011. Hard choices: Making trade-offs between biodiversity conservation and human well-being. Biological Conservation, 144(3): 966-972.

MEA, 2005. Ecosystems and Human Well-being: Scenarios: Findings of the Scenarios Working Group. Island Press.

Medcalf K, Small N, Finch C et al., 2014. JNCC Report No: 514. Further Development of a Spatial Framework for Mapping Ecosystem Services.

Mouchet M A, Lamarque P, Martín-López B et al., 2014. An interdisciplinary methodological guide for quantifying associations between ecosystem services. Global Environmental Change, 28: 298-308.

Naidoo R, Ricketts T H, 2006. Mapping the economic costs and benefits of conservation. PLoS Biology, 4(11): e360.

Nelson E, Mendoza G, Regetz J et al., 2009. Modeling multiple ecosystem services, biodiversity conservation, commodity production, and tradeoffs at landscape scales. Frontiers in Ecology and the Environment, 7(1): $4-11$.

Nelson E, Polasky S, Lewis D J et al., 2008. Efficiency of incentives to jointly increase carbon sequestration and species conservation on a landscape. Proceedings of the National Academy of Sciences, 105(28): 9471-9476.

Nguyen T T, Verdoodt A, Van Y T et al., 2015. Design of a GIS and multi-criteria based land evaluation procedure for sustainable land-use planning at the regional level. Agriculture, Ecosystems \& Environment, 200: 1-11.

Paterson S, Bryan B A, 2012. Food-carbon trade-offs between agriculture and reforestation land uses under alternate market-based policies. Ecology and Society, 17(3): 21.

Pattanayak S K, 2004. Valuing watershed services: Concepts and empirics from Southeast Asia. Agriculture, Ecosystems \& Environment, 104(1): 171-184.

Polasky S, Nelson E, Camm J et al., 2008. Where to put things? Spatial land management to sustain biodiversity and economic returns. Biological Conservation, 141(6): 1505-1524.

Polasky S, Nelson E, Pennington D et al., 2011. The impact of land-use change on ecosystem services, biodiversity and returns to landowners: A case study in the State of Minnesota. Environmental and Resource Economics, 48(2): 219-242.

Power A G, 2010. Ecosystem services and agriculture: Tradeoffs and synergies. Philosophical Transactions of the Royal Society B: Biological Sciences, 365(1554): 2959-2971. 
Raudsepp-Hearne C, Peterson G D, Bennett E, 2010. Ecosystem service bundles for analyzing tradeoffs in diverse landscapes. Proceedings of the National Academy of Sciences, 107(11): 5242-5247.

Ring I, 2008. Biodiversity governance: Adjusting local costs and global benefits. In: Public and Private in Natural Resource Governance: A False Dichotomy? London, UK: Earthscan.

Ring I, Hansjürgens B, Elmqvist T et al., 2010. Challenges in framing the economics of ecosystems and biodiversity: The TEEB initiative. Current Opinion in Environmental Sustainability, 2(1): 15-26.

Rockström J, Steffen W, Noone K et al., 2009. A safe operating space for humanity. Nature, 461(7263): $472-475$.

Rodríguez J, Beard T, Agard J et al., 2005. Interactions among ecosystem services. Millennium Ecosystem Assessment (ed.). Ecosystems and Human Well-being: Scenarios (Vol. II). Washington, DC: Island Press.

Rodríguez J P, Beard T D, Bennett E M et al., 2006. Trade-offs across space, time, and ecosystem services. Ecology and Society, 11(1): 28.

Ruhl J B, Kraft S, E, Lant C L, 2007. The Law and Policy of Ecosystem Services. Cambridge Univ Press.

Ryffel A N, Rid W, Grêt-Regamey A, 2014. Land use trade-offs for flood protection: A choice experiment with visualizations. Ecosystem Services, 10: 111-123.

Sanon S, Hein T, Douven W et al., 2012. Quantifying ecosystem service trade-offs: The case of an urban floodplain in Vienna, Austria. Journal of Environmental Management, 111: 159-172.

Seppelt R, Lautenbach S, Volk M, 2013. Identifying trade-offs between ecosystem services, land use, and biodiversity: A plea for combining scenario analysis and optimization on different spatial scales. Current Opinion in Environmental Sustainability, 5(5): 458-463.

Sheng W P, Ren S J, Yu G R et al., 2011. Patterns and driving factors of WUE and NUE in natural forest ecosystems along the North-South Transect of Eastern China. Journal of Geographical Sciences, 21(4): 651-665.

Silvestri S, Kershaw F, 2010. Framing the flow: Innovative approaches to understand, protect and value ecosystem services across linked habitats. United Nations Environment Programme (UNEP).

Swallow B M, Sang J K, Nyabenge M et al., 2009. Tradeoffs, synergies and traps among ecosystem services in the Lake Victoria basin of East Africa. Environmental Science \& Policy, 12(4): 504-519.

Tallis H, Kareiva P, Marvier M et al., 2008. An ecosystem services framework to support both practical conservation and economic development. Proceedings of the National Academy of Sciences, 105(28): 9457-9464.

Tallis H, Ricketts T, Guerry A et al., 2011. InVEST 2.1 beta User's Guide. The Natural Capital Project. Stanford.

Tansley A G, 1935. The use and abuse of vegetational concepts and terms. Ecology, 16(3): 284-307.

TEEB, 2010. In: Kumar P (ed.). The Economics of Ecosystems and Biodiversity: Ecological and Economic Foundations. London: Earthscan.

Tietenberg T, 1988. Environmental and Natural Resources. Economics.

Tilman D, Cassman K G, Matson P A et al., 2002. Agricultural sustainability and intensive production practices. Nature, 418(6898): 671-677.

UKNEA, 2011. The United Kingdom National Ecosystem Assessment: Technical Report. Cambridge, UK: UNEP-WCMC.

van den Belt M, Bowen T, Slee K et al., 2013. Flood protection: Highlighting an investment trap between built and natural capital. JAWRA Journal of the American Water Resources Association, 49(3): 681-692.

Van Huylenbroeck G, 1997. Multicriteria tools for the trade-off analysis in rural planning between economic and environmental objectives. Applied Mathematics and Computation, 83(2): 261-280.

Varian H R, Repcheck J, 2010. Intermediate Microeconomics: A Modern Approach. New York: WW Norton.

Vollmer D, Pribadi D O, Remondi F et al., 2015. Prioritizing ecosystem services in rapidly urbanizing river basins: A spatial multi-criteria analytic approach. Sustainable Cities and Society, 20: 237-252.

Wang Z, Mao D, Li L et al., 2015. Quantifying changes in multiple ecosystem services during 1992-2012 in the Sanjiang Plain of China. Science of the Total Environment, 514: 119-130.

Wendland K J, Honzák M, Portela R et al., 2010. Targeting and implementing payments for ecosystem services: Opportunities for bundling biodiversity conservation with carbon and water services in Madagascar. Ecological Economics, 69(11): 2093-2107.

Willemen L, Veldkamp A, Verburg P et al., 2012. A multi-scale modelling approach for analysing landscape service dynamics. Journal of Environmental Management, 100: 86-95.

Yahdjian L, Sala O E, Havstad K M, 2015. Rangeland ecosystem services: Shifting focus from supply to reconciling supply and demand. Frontiers in Ecology and the Environment, 13(1): 44-51. 